\title{
'Meaningful participation': Exploring the value of limited participation for community radio listeners
}

Bridget Backhaus, Griffith University

\begin{abstract}
Community radio represents an opportunity for audiences to play a lead role in the production, dissemination and ownership of media channels and content. The active participation of audiences is one of the primary differences between community radio stations and their commercial and state-run counterparts. The role of participation though is complicated in environments where community radio acts as an instrument for development, as is the case in India where community radio licenses are held by either educational establishments or nongovernmental organizations (NGOs). Discussions around defining, encouraging and evaluating participation are extensive, yet little has been written about what defines meaningful participation from the perspective of community members. Drawing on ethnographic fieldwork in India, this article explores what makes participation meaningful and who is able to engage in this meaningful participation with community radio stations. Applying this perspective to community radio, encourages a more qualitative, holistic view of the benefits and outcomes of those who participate. Considering meaningful rather than maximalist or minimalist allows space to explore the impacts of participation in environments where it may be limited or restricted by structural factors. Engaged, invested audiences who regularly and meaningfully participate in their stations can help ensure that community radio remains a collaborative and powerful force within the global media landscape.
\end{abstract}


Keywords

community radio

participation

development

meaningful participation

ownership

voice

agency

\section{Introduction}

Community radio has traditionally been a bastion of participation. In his much-cited definition, Louie Tabing describes community radio as 'in the community, for the community, about the community and by the community' (2005: 9). Participation is implied at every level as Siemering puts it: 'everyone has a right to be on community radio' (2000: 374). Participation of the community represents an intrinsic part of what separates community radio from its commercial and state-run counterparts (Banjade 2007; Forde 2015). The archetypal community radio station would be one that embraces maximalist participation, and encourages and facilitates community involvement at every level, from production to management (Carpentier et al. 2003; Girard 1992). However, this is not always the case. An array of structural, social and political factors may serve to limit the extent to which communities are able to fully participate in their local community radio stations. As White explains 'sharing through participation does not necessarily mean sharing in power' (1996: 6). 
The limitations of participation in community radio are particularly clear in environments with a dominant development agenda. Though community radio stations all over the world serve a multitude of different purposes, in India, community radio is 'development, development, development' (Bailur 2008, 2015). The question that arises then, is the role of participation in such an interpretation of community radio. Does a focus on development act to support or subvert participation in community radio?

Given the limitations that surround participation in community radio, this article argues for a deeper discussion of participation in community radio: for considering depth rather than breadth. While there have been endless discussions about defining, encouraging and evaluating participation, meaningful participation is a concept that is far less explored. What makes participation, even limited or restricted participation in community radio, meaningful for those involved? While this is clearly a broad question with no singular answer, this article offers a starting point by drawing on the findings of qualitative research conducted at two community radio stations in South India. The concept of meaningful participation provides insight into how meaning and value can still be derived from situations of limited or restricted participation. While meaningful participation in community radio may not necessarily mean a seat at board meetings or open access to studio time, it remains a valid and valuable outcome for community radio stations working towards development goals.

\section{Community radio and participation}

An all-encompassing definition of community radio is elusive (Carpentier et al. 2003). Community radio stations may take radically different approaches to ownership, organizational structure, funding, technological design and content (Hussain and Tongia 2007). A recurring theme throughout the literature however relates to the importance of community participation in 
community media. Meadows et al. refer to participation in community media as 'a site of empowerment' (2007: 13). Rodriguez suggests that, by participating in community media, 'communities are actively enacting citizenship' (2001: 158). Carpentier et al. consider participation of the community to be one of the 'key defining factors' of community media (2003: 54-55). Participation is also crucial to understanding the value of community media. Fraser's (1990) work on alternative public spheres offers a clear conceptualization of the importance of democratized access to media production. Participation and community radio are intricately linked, though it is essential to bear in mind the role of power in this relationship. Community radio, despite the idealism, remains subject to the participatory and democratic processes of society and the subsequent power struggles at work (Bailur 2012). While discussions around participatory processes within community radio stations are invaluable, it is also necessary to discuss the broader context. Katiyar observes that 'the participation of the community seems to imply that the motivation for participation by a community is inherent' (2017: 326). In reality, it is the wider power relations that condition these interests (White 1996). Participation in community radio has been defined in a number of ways ranging from minimalist approaches, where participation is limited to just access, to maximalist, holistic approaches which see participation at all levels of content and management (Carpentier 2015, 2016). Indeed, the appeal of a term like 'participation' is that its conceptual vagueness and malleable applications across a range of disciplines have meant that it can mean 'everything and nothing' (Carpentier 2011: 14). In search of a more concrete definition of participation, Carpentier considers two main approaches to defining participation: sociological and political. A sociological approach interprets participation as simply 'taking part in particular social processes', while a political definition is far more restrictive, arguing that participation refers to 
the 'equalisation of power relations between privileged and non-privileged actors in formal or informal decision-making processes' (Carpentier 2015: 71-72). That is not to say that every form of participation necessarily involves ousting the powerful. Arnstein considers participation to be a categorical term for power and outlines the various levels of participation and 'nonparticipation' on her famed ladder (1969). It is really only the topmost rungs ('partnership', 'delegated power' and 'citizen control') where citizens experience any sort of 'decision-making clout' (Arnstein 1969: 217). While participation in community radio is often viewed through a purely sociological lens, it is valuable to take a political perspective so as to interrogate who is able to participate and how. This is further complicated for community radio stations working within a development agenda. When Robert Chambers posed his seminal question '[w]hose reality counts?', the answer was, invariably, that power determines not just whose reality counts, but also whose knowledge counts and how (1995; Ramalingam 2013). While community radio is widely accepted as a participatory medium, taking a closer, more critical look at participation in community radio reveals complex power relations heavily dependent on local context.

\section{Community radio in India}

Given the importance of context to participation in community radio, it is essential to discuss the social, political and historical environment in which this research took place. Community radio occupies a small space in India's megalithic media landscape, an environment which Pavarala and Malik describe as 'dominated by hierarchical, paternalistic public and profit-oriented commercial models of broadcasting' (2007: 243). Community radio in India has a history of struggle that has shaped its contemporary broadcasting environment.

The Indian Government has historically kept a tight grip on broadcasting rights. The Indian Telegraph Act (1885) along with the Indian Wireless Telegraphy Act (1933) effectively 
meant that the possession of radio equipment without a license was illegal, granting exclusive broadcasting rights to the Central Government (Kumar 2003; Pavarala and Malik 2007). This created a broadcasting environment where the state broadcasters (All India Radio and television broadcaster Doordashan) were essentially propaganda mouthpieces where 'big people continue to address small people' (Kumar 2003: 2179). It was not until 1995 that the Supreme Court made a landmark ruling that paved the way for community radio and, indeed, a more open and free media environment. The Supreme Court ruled that the 'airwaves are public property' and should be used for public benefit (Singhal and Rogers 2001; Sen 2003; Pavarala and Malik 2007; UNESCO 2011). It still took another five years for the public broadcasters to gain relative autonomy from the government (Singhal and Rogers 2001), but the Supreme Court's ruling was of critical importance not only to only to the public broadcasters and communication rights more generally, but also for the community radio movement.

In 1996, a group of policy experts and media workers gathered in Bangalore to discuss the relevance of community radio for India. The 'Bangalore Declaration on Radio' made a strong case for community radio, describing it as 'public service broadcasting in its most decentralised and its most democratic form' (Sen 2003: 2199). The first systematic case for establishing community radio as the third-tier of broadcasting in India was made in 2000 by a group of activists, academics and practitioners (Pavarala 2013). The declaration resulting from the meeting, which was supported by UNESCO, was known as the 'Pastapur Initiative on Community Radio', named after the area in which the meeting occurred (Sen 2003). In late 2002, the Ministry of Information and Broadcasting finally released the 'Community Radio Guidelines', which restricted licenses to 'well-established' educational institutions and banned news, current affairs and advertising (SANCOM 2015). While this was not quite the victory that 
the community radio movement was hoping for, the guidelines did lead to the establishment of India's first community radio station at Anna University in Chennai, which began broadcasting in February 2004 (Prabakar 2009; Ghosh 2011; Nirmala 2015).

The following years marked a renewed push which eventually, in late 2006, saw the Indian Telegraph Act (1885) amended to include a second phase of community radio guidelines (UNESCO 2011). Alongside educational institutions, NGOs and agricultural science centres became eligible to apply for licenses. News was still not permitted but limited advertising was allowed (SANCOM 2015). In October 2008, Sangham Radio in Pastapur village became the first community radio station licensed to an NGO (Pavarala and Malik 2007; Ghosh 2011).

It is now more than ten years since these updated guidelines were released and community radio in India is at a crossroads. Malik suggests that the movement has plateaued '[w]hile there is recognition and acceptance of its potential in the upper echelons of administration, it looks as if there is a decline in buy-in from grassroots practitioners and communities in India' (2016). As of May 2018, India had just 217 operational community radio stations (Ministry of Information and Broadcasting 2018), as opposed to the 3000 or 4000 stations that the country's size, population and diversity could accommodate (Kumar 2018). The community radio sector is also facing the problems associated with 'NGO-ization'; stations find themselves forced to conform to the agenda of their parent NGOs that are, in turn, under pressure from donors to 'scale up' operations and demonstrate their impact (Malik and Bandelli 2012; Pavarala 2015). Furthermore, questions are also being raised about the more fundamental role of the community radio sector in India. Development forms a key part of the regulatory rationale, which Pavarala considers to be a legacy of postcolonial nation-building. He argues that the sector 
should focus on communication rights rather than a developmentalist agenda (Pavarala 2015). Bailur offers a telling quote from one of her research participants:

These days you have to keep telling them what to do [...] development, development, development. We can either approach community radio as what the community wants [...] if you make it that, it will only be music. At [the donor agency], we can't justify all this equipment just for entertainment, there has to be a development angle. You have to keep pushing programming in a certain direction. (2008: 11)

To summarize, establishing community radio in India has been a long and difficult journey. Currently, many stations are facing internal issues associated with sustainability and independence. The sector as a whole must operate within a rigid, tightly controlled regulatory environment. In stark contrast with the free-for-all of commercial broadcasting, community radio stations must adhere to strict rules on revenue-generating advertisements (Thomas 2010). Alongside this, there remain restrictions on the broadcasting of news content, and licenses are still only granted to educational institutions, agricultural colleges and well-established NGOs. These factors have had a stifling effect on the sector as evidences by the relatively small number of stations for a country of India's size and diversity.

\section{Research sites}

This article is informed by research conducted at two community radio stations in Tamil Nadu between March and September 2017. The research sites are located in Tamil Nadu, a state in South India bordered by Kerala to the west, Karnataka and Andhra Pradesh to the north and the Indian Ocean to the east. Tamil Nadu is the seventh largest state in India by population and the 
eleventh largest by area (Office of the Registrar General \& Census Commissioner 2011). The population is split relatively equally between urban and rural areas with approximately $46 \%$ of the land area used for agricultural cultivation (Department of Economics and Statistics 2017). Tamil Nadu has a long history with local, participatory radio projects and experiments in community broadcasting, and therefore represents a promising site for explorations of community radio. In the 1960 s, Tamil Nadu was the site of some early experiments in community broadcasting by linking agricultural extension services with farmers (Page and Crawley 2001). In the 1970s, Tamil Nadu was also the site of experiments in encouraging greater participation from listeners. The participatory model was radically different from the top-down approach of the state broadcaster, and, at the time, was thought to represent a viable model for other stations (Page and Crawley 2001). Tamil Nadu was also the site of the very first iteration of community radio in India, Anna FM, located in the state capital, Chennai. Perhaps because of this, campus radio has a strong presence within the community radio landscape of Tamil Nadu with 24 out of the 31 stations, or more than $75 \%$, associated with educational institutions (Ministry of Information and Broadcasting 2018). This is higher than the national ratio which sees roughly $60 \%$ of operational community radio station affiliated with educational institutions. As of May 2018, there are 31 operational stations in Tamil Nadu (Ministry of Information and Broadcasting 2018). This is particularly noteworthy given that Tamil Nadu is the seventh largest state by population yet has the highest number of community radio stations (Office of the Registrar General \& Census Commissioner 2011; Ministry of Information and Broadcasting 2018). In comparison, the most populous state - Uttar Pradesh - which has more than double the population of Tamil Nadu, has just 24 stations. 
The stations themselves were selected based on their ownership models, their rural locations and their relatively close proximity to major centres, for logistical reasons. The descriptions of the sites themselves are general and aim to offer the bare minimum identifiable information while still providing sufficient context. Though the names of the stations have been changed, those readers deeply familiar with the community radio sector in Tamil Nadu and India will likely have a fair idea of the true identity of the stations. Interviewees and informants are referred to in this article with minimal identifying information, usually only which station they are associated with and their general relationship to that station - audience or staff. Taking the approach of lightly disguising the research sites while masking the identities of the specific people involved was deemed to be most ethically appropriate for this research.

Station One is located just outside of a small village in a forested, hilly area that is either densely forested or blanketed in tea plantations. The station is part of a well-established NGO that was been working in the region for many years. The NGO focusses on environmental sustainability, biodiversity and supporting local indigenous tribal communities in preserving their traditional knowledge. There are a number of culturally and linguistically different tribes in the area, with some maintaining isolated traditional lifestyles deep in the forest. Station One broadcasts primarily in Tamil with some programming in several local tribal languages as well. The station broadcasts to a 15-kilometre area around the village, though their actual coverage is heavily affected by the landscape. The villages closest to the station in valleys often struggle to get signal while competition is fierce in the hilltop villages as listeners can tune in to popular FM stations in major cities hundreds of kilometres away.

Station Two is also a rural station located in a small village, about one hour's drive from a large and prosperous town. The area is largely agricultural with farmers growing a variety of 
crops depending on the season and markets. With funding support from an NGO, a farmer's federation was established to promote water management and improve access to government services. Though primarily focussed on water conservation and management, the federation has broadened its scope to other community development activities including the provision of technology centres with computer and Internet facilities, as well as supporting a community radio station. The station has a broadcasting range of $15 \mathrm{~km}$, which covers much of the surrounding villages. The station broadcasts in Tamil, mainly around the themes of agriculture and health.

\section{Methodology and methods}

The methodology of this research was qualitative and heavily influenced by ethnography. Adopting a bricolage approach, this research drew on ethnographic methods and tools alongside other methods so as to address the research questions and adapt to any unexpected challenges that emerged. Data were collected through participant observation, focus group discussions with listeners, and interviews with radio station staff. An initial period of observation took place at the station itself prior to any interviews in order to understand the day-to-day operations, and also to situate the station within its broader community context. The second stage of observation drew from Kusenbach's (2003) 'go-along', a technique that employs both observation and informal interviewing while accompanying participants on their everyday outings. Following these initial contextualizing periods of observation, a series of interviews were conducted with station staff and listeners with the aim of collecting descriptive, qualitative data. Listener focus groups were conducted first by drawing on Meadows et al.'s (2005) approach to focus group recruitment, in which they sought the assistance of broadcasters in identifying and forming focus groups, which they later also participated in. After identifying and seeking permission from these key listeners, 
rhizomatic sampling (Akindes 2003), based on those with connections to the station and to other focus group members, was used to create focus groups consisting of participants who were also regular listeners and shared demographic traits. This resulted in six focus groups of between four and seven participants which took place in different places within the broadcast range of the stations. In addition to listeners, who had only interacted with the radio station by listening to programmes, the focus groups included listeners who had participated in station activities, such as events or interviews, volunteers, as well as some members of the stations' parent bodies. Following the listener focus groups, group interviews were conducted with station staff and, finally, one-on-one interviews with key informants from the stations. A total of six listener focus groups, two group interviews with station staff, and two one-on-one interviews with station managers were conducted. The primary method of data analysis was constructivist grounded theory. While grounded theory traditionally aligned with positivist and post-positivist research (Clarke 2007; Spencer et al. 2014), it was adapted to constructivist inquiries by Kathy Charmaz (2014). She writes that, in contrast to Glaser and Strauss 'discovering' grounded theory, neither data nor theories are discovered, but constructed (Charmaz 2014). Any resulting theories are interpretive portrayals, rather than exact representations of the studied world: 'We construct our grounded theories through our past and present involvements and interactions with people, perspectives, and research practices [...] Participants' implicit meanings, experiential views and researchers' finished grounded theories - are constructions of reality' (Charmaz 2014: 10).

\section{Results and discussion}

The findings of this research reveal a variety of factors influencing the breadth and depth of participation in community radio in India. Participation in community radio is often limited by 
the structures of the medium as well as the socio-economic environment in which it takes place. Rather than dismissing this as 'minimalist' or limited participation, what was consistently observed throughout the research were examples of the value or meaning of participation under these circumstances. It became evident that there was a need for a broader view of participation that considers local context and individual experiences. This section discusses the limited or restricted participation that was observed over the course of the research, and then introduces the concept of meaningful participation. Meaningful participation acts as a way of understanding participatory experiences that may not redress power imbalances or even traditionally be defined as participation, but that hold meaning and value for those involved.

\section{Limited or restricted participation}

What emerged from the data is a very different model of participation than the one idealized by community radio rhetoric. One of the key findings of this research is about the various structures influencing the breadth and depth of participation in community radio in India. Carpentier, who has written extensively on participation and alternative media, refers to 'minimalist' and 'maximalist' models of participation to describe the level of control retained by professionals and the 'intensity' of participation. He suggests that, in minimalist forms of participation, media professionals are 'retaining strong control over process and outcome', while maximalist models of participation balance the power relations between 'media professionals and non-privileged groups' (Carpentier 2016: 84). In an earlier work, he writes of structural participation: participation that only occurs within the media organization's decision-making structures (Carpentier 2015). Though Carpentier is referring primarily to mainstream media in this particular work, these kinds of structural limitations were observed throughout the research. There seemed to be several different types of limitations or restrictions on participation. 
Firstly, the contextual environment plays a significant role in limiting or restricting how communities can participate in community radio in India. As discussed, community broadcasting legislation in India restricts ownership models to educational institutions, well-established NGOs and agricultural science centres. This in itself significantly impacts on the amount of 'true' participation or representation a community radio station can aim to achieve. Of the two stations visited, the station with the most distance from its parent body, both in organizational structure and physical proximity, seemed to enjoy the most autonomy.

Furthermore, the development discourse underpinning the sector also serves to limit participation, or at least stifle the facilitation of further participation. Relating back to the work of Bailur (2008), mentioned earlier, the key work of the stations is not necessarily focussed on encouraging participation, but on achieving the development goals of their parent body. This development discourse in action was observed at Station Two, which had a clear agricultural focus. Much of their broadcasting time was spent extolling modern farming techniques in order to increase crop yields and improve environmental sustainability. While the listenership, who were predominantly farmers, appreciated the targeted material, the region was in a drought and there was very little agriculture actually taking place. The station was obliged to maintain the focus of its parent body, despite the disconnect with the listeners and the situation in the local community.

A further influencing factor that serves to limit or restrict who can participate in community radio, and how, relates to social structures. Cleaver (2001) writes that in terms of individual action and participatory initiatives, the impact of social structures is under-researched and they are variously perceived as both opportunities and constraints. Though any thorough discussion of Indian society and culture falls outside the scope of this article, the effects of 
gender, class and caste cannot be discounted when it comes to community radio. Shah argues that simplistic interpretations of the term implies that communities are homogeneous, static and harmonious units (1998). Use of the term in this way conceals power relations and biases based on age, gender, class, caste and religion (Shah 1998). As discussed, power relations impact both implicitly and explicitly on who is allowed to participate and how they do so. Any attempt at community representation is limited by both the arbitrary power structures of society and the practical limitations of achieving representation (Katiyar 2017). This framework of impossibility is indirectly acknowledged by policy-makers, who instead turn their focus to ensuring that the 'needs of the local community get relevance through the programming' (Katiyar 2017: 325). Such an environment makes maximalist participation in community radio in India functionally impossible. Participation at the grassroots is limited by social and cultural factors, while participation in upper levels of management is restricted by the legislative requirements.

\section{Meaningful participation}

While the concept of limited or restricted participation paints a bleak and somewhat contradictory picture of community radio in India, what emerged from the data was quite different. Rather than lamenting a 'lack' or 'restricted' form of participation in their local community radio station, participants repeatedly expressed what they had gained from their participation, in whatever form it took. This prompted a re-examination of participation and how it is viewed in community radio and development literature. Though a number of models have been developed with the aim of exploring various facets of participation in terms of both media and development (see Carpentier 2016; Pretty 1995; White 1996, among others), the quality and effects of participation at a grassroots level are far less understood. 
The concept of 'meaningful mobility' was introduced by Tacchi et al. (2012) in their work on mobile phones and development in India. They argue that there is an over-emphasis on economic development in the field of Mobiles for Development (M4D, see Donner 2010) which has led to a narrow view of the meanings attached to communication technologies. There is an entire spectrum of intangible benefits that such a narrow view fails to recognize: 'personal empowerment, gender equity, emotional fulfilment, etc' (Tacchi et al. 2012: 530). Applying this perspective to another form of technology, community radio, encourages a more qualitative, holistic view of the benefits and outcomes of those who participate. Considering 'meaningful' rather than maximalist or minimalist allows space to explore the impacts of participation in environments where it may be limited or restricted by structural factors. Hence, the concept of meaningful participation emerged as a lens for viewing the research findings.

'Meaningful' is a loaded term, imbued with any number of interpretations based on the context and discipline through which it is employed. Countless literature exists debating and defining what is 'meaning' and what can be considered 'meaningful'. For the purpose of this research however, it suffices to take an intersubjective ontological view of the term, though meaning takes shape within the minds of individuals, it comes to exist through communicative dialogue with others (Leontiev 2005). A deliberately broad interpretation was employed throughout this research in order to allow a definition to emerge from the data. Based on this, through drawing on the research findings and the previously conducted work on meaningful mobilities (Tacchi et al. 2012; Tacchi 2014), a number of themes emerged relating to different facets of what could be considered meaningful. 


\section{Ownership}

The foremost theme that emerged within the broader topic of meaningful participation was that of ownership. This is perhaps unsurprising as ownership appears regularly in participatory development literature as a critical factor impacting upon participant buy-in (Gumucio-Dagron 2001; Tufte and Mefalopulos 2009), as well as in relation to community media, where community ownership represents somewhat of an ideal model (Carpentier 2015; Tabing 2005). In terms of meaningful participation though, ownership is not only about property, but rather encompasses 'individual identity, agency and well-being - including what Gandhi described as swaraj (self-rule or self-reliance)' (Tacchi et al. 2012: 533).

Ownership as a manifestation of meaningful participation was observed throughout the research in several different ways. First, in perhaps a more traditional interpretation, ownership was discussed at length between members of Station Two's parent body, a farmer's federation. There was a strong sense of ownership over the station among this group, and rightfully so.

It was started for the purpose of the farmers. It was for farmers and, as a farmer, I felt it was my radio. For example, if I own a watch, I will have the feel that it belongs to me. But if I watch time from other's watch I won't feel it is mine. The same way I felt this as my radio from day one. (Station Two listener and parent body member)

Despite the fact that this particular listener had participated in just a handful of interviews with the station over the years and his participation was primarily through listening to the radio, there was a strong sense of pride and ownership.

In different groups however, notions of ownership emerged in distinctly different ways. 
Among the female volunteers at Station Two, ownership emerged through local links with a staff member.

At first, the people at home protested and did not allow us go anywhere. But now they have slowly started to understand what we are doing. [Station Two staff member] has a great role in that. She came door-to-door and encouraged us to participate, and we have also benefitted through it. We are very proud that a woman from our village is doing so much for the community. We are also determined to become like her. (Station Two listener and volunteer)

Participation emerges in some way throughout two these examples. From the perspective of the parent body, listeners are more likely to participation because they are represented; from the perspective of a volunteer, she was able to participate due to her community's sense of ownership of a local staff member. A combination of factors - a sense of ownership, representation and social interaction - contribute to a listener's willingness to participate. This illustrates a complex web of empowerment and meaning that simultaneous prompts and results in participation.

Agency

Earlier we used to be at home. Nowadays we travel a lot. At first, the people at home protested and did not allow us to go anywhere. Earlier our husbands won't allow us to travel like this alone. But now they are allowing us, now after we explained what we are doing, they have slowly started to understand. (Station Two volunteer) 
Related to ownership, agency also represents an important aspect of meaningful participation. Dahlgren and Alvares explicitly refer to participation as 'an expression of agency' (2013: 48). It is through such 'expressions' that citizens are able to extend and exert their rights as members of political communities and subsequently leverage greater control over socio-economic resources (Hickey and Mohan 2004). Jacobson, drawing on the work of Sen, argues that agency forms part of the conceptual basis of understanding development as freedom - the freedom to choose the kind of life one has reason to value (Sen 1999; Jacobson 2016). Agency clearly represents an important facet of a freedom-based interpretation of development, it was also observed as a key outcome of meaningful participation in community radio.

By far the most common examples of agency that were observed throughout the research related to women's empowerment. Participation in local community radio stations, even at the level of simply being interviewed for a programme or volunteering to conduct listener surveys in their local village, had a profound effect on women. This is of particular importance because often, even where participation has resulted in increased agency for other community members, there are those within the community whose voices are silenced (Dutta 2014). From a development perspective, Amartya Sen argues that women's agency and voice influences the nature of other public discussions, 'freedom in one area (that of being able to work outside the household) seems to help to foster freedom in others' (1999: 194). The earlier quote illustrates the increased agency that some women were able to exercize as a result of their volunteer work with their local community radio station. Interestingly enough, rather than any specific initiative or development project run by the community radio station, it was a female staff member who, through her social interactions and respected position in the community, used her power to persuade a group of women, and their families, to volunteer. The results of her work frequently 
appeared in the findings of the research, with many female volunteers at this particular station mentioning this staff member by name and crediting her with their increased confidence and freedoms. In terms of participation, the volunteering involved conducting listener surveys and being interviewed for different radio programmes. This could hardly be considered 'maximalist' participation by Carpentier's definition, nor does it represent any particular power shift from the producer of content to the listeners, yet it presents an example of meaningful participation in action. This group of volunteers clearly perceived significant value resulting from their work, despite the supposedly 'limited' nature of their participation.

\section{Voice}

Voice represents a particularly important aspect of meaningful participation in community radio. Voice has variously been associated with 'personhood', 'individuality', embodiment and the right to engage in social and political discourse (Appadurai 2004; Couldry 2004; Kunreuther 2012; Tacchi et al. 2009). Defying simple definition, voice references 'inclusion and participation in social, political, and economic processes, meaning making, autonomy, and expression' (Tacchi 2009: 169). In terms of the personal aspects, voice is a basic dimension of human life and constitutes of an intimate account of one's life and its conditions (Couldry 2015). Cornwall differentiates participatory processes from voice, arguing that though these processes may create space, 'voice needs to be nurtured. People need to feel able to express themselves without fear of reprisals or the expectation of not being listened to or taken seriously' (Cornwall 2008: 278). Community radio presents an opportunity to create such space. Indeed, Couldry (2015) suggests that alternative media, including community radio, acts as the social application of both the speaking and listening that are the social processes of voice. 
The notion of voice is also where meaningful participation intersects with development thought. Tacchi and Kiran discuss 'voice poverty' as 'the denial of the right of people to influence the decisions that affect their lives, and the right to participate in that decision making' (2008: 31). As it relates to media, voice poverty sees groups with limited access to mass media denied opportunities for political participation and self-expression (Malik 2012). This is representative of a media landscape where freedom of speech and expression through the media is possible only for the powerful (Malik 2012; Pavarala 2015). Community media have a role to play in the democratization of media landscapes, with Couldry (2015: 51) arguing that community media should function as the collective process for the "production, sustaining and enacting of collective voice'. How this occurs in practice, however, is unclear.

Despite the significant theoretical support for the concept of voice as it applies to community radio and development, the research data yielded distinctly different results. While broadcasters consistently identified voice as one of their key contributions to listeners, the same was could not be said of listeners. The contrast can be observed in the following interview:

Some people cannot bring out their voice. We need give them a voice through radio. So, it is basically giving voice to the voiceless. (Station One broadcaster)

They find happiness in hearing their voice and informing their friends and family about their participation. (Station Two broadcaster)

While broadcasters echoed the community radio rhetoric of a 'voice for the voiceless' and discussed voice at length, listeners spoke more on the personal aspects of hearing their voice on the radio. 
We will feel very happy while we hear our own voice in the radio. We feel proud of ourselves for the content we have spoken. (Station Two listener)

We ourselves are surprised listening to our voices in the radio. We cannot believe if it is our work. (Station One listener)

More political interpretations of voice, as it applies to democratization of the media and so forth, failed to emerge in discussions with listeners. This is not to discount or minimize the experiences and realizations of voice for these listeners, quite the opposite. As Kanchan Malik (2012) wrote in a piece for Indian media watchdog The Hoot: 'Indeed, for those who have traditionally been unacknowledged and silenced, socially and culturally, the opportunity to have one's voice heard can be an imposing experience of self-worth'.

Closely related to voice is the concept of listening. As one listener explained: 'We speak in many places and that's different. But in radio, people listen to what we speak.' What is implied by this quote is that the power associated with speaking on radio somehow means that their voice is more likely to be listened to and taken seriously, both key factors to realizing voice. Returning to the original discussion of levels of participation in community radio, does an interview constitute participation in community radio? This particular listener spoke with great enthusiasm about the first time she spoke on the radio, and how she gathered her friends and family together to listen to the broadcast. She was proud that her opinions were valued enough to be broadcast. Similarly, the listeners quoted earlier expressed pride and a sense of accomplishment resulting from their experiences within the community radio station which, for the most part, consisted of being interviewed and then hearing themselves broadcast on the radio. Though perhaps being interviewed could be interpreted as falling within the category of 
'minimalist', content-driven participation, it is evident that there has been significant meaning derived from these experiences from the perspective of the listeners.

\section{Conclusion}

To conclude, while a maximalist approach to participation in community radio remains a noble goal, there are many situations where such an ideal is unrealistic due to a range of external and internal factors, whether political, financial or legislative. In the case of community radio in India, the overarching development discourse, reinforced by strict legislature, serves to limit how the community can participate. Limitations on ownership and funding, alongside social structures, serve to restrict the ways in which audience members are able to participate.

When working within these frameworks of impossibility, it is valuable to take a broader view of participation: to employ more nuance than is considered in the prominent maximalist/minimalist discussions of participation. Value and meaning can still be derived from limited or restricted participatory experiences. Drawing on qualitative research conducted at two stations in South India, the concept of meaningful participation was developed in order to encourages a broader, more holistic view of the benefits and outcomes of those who participate, despite the 'limited' nature of the participation. Considering 'meaningful' rather than maximalist or minimalist allows space to explore the impacts of participation in environments where it may be limited or restricted by structural factors. There are several facets of meaningful participation, including ownership, agency and voice that were observed consistently throughout the research. It was clear that, despite the structural limitations on the breadth and depth of participation, community radio listeners at these stations were finding value in the participation they were able to partake in. As such, discussions on participation that only consider scope and breadth fail to capture the nuance of participation in community radio in India. Value and meaning can still be 
derived from limited or restricted participatory experiences, the challenge lies in finding cases of meaningful participation and exploring how to expand these opportunities for others.

\section{References}

Akindes, Fay (2003), 'Methodology as lived experience: Rhizomatic ethnography in Hawai'i', in

P. Murphy and M. Kraidy (eds), Global Media Studies: Ethnographic Perspectives, London: Routledge, pp. 147-64.

Appadurai, Arjun (2004), 'The capacity to aspire', in V. Rao and M. Walton (eds.), Culture and Public Action, Stanford: Stanford University Press.

Arnstein, Sherry R. (1969), 'A ladder of citizen participation', Journal of the American Institute of Planners, 35:4, pp. 216-24.

Bailur, Savita (2008), ‘Analyzing telecentres using postcolonial theory', Paper No. 35:

Development Informatics Working Paper Series, Manchester: Institute for Development Policy and Management.

(2012), 'Who is the community in community radio?', Economic \& Political Weekly,

47:17, pp. 92-99.

(2015), “'Development, development, development”: Rules and norms performed at a "community" multimedia centre in South India', in G. F. Lanzara, F.-X. de Vaujany, N. Mitev, 
and A. Mukherjee (eds.), Materiality, Rules and Regulation: New Trends in Management and Organization Studies, London: Palgrave Macmillan, pp. 52-72.

Banjade, Arjun (2007), Community Radio in Nepal: A Case Study of Community Radio Madanpokhara, Athens, $\mathrm{OH}$ : Ohio University.

Carpentier, Nico (2011), 'The concept of participation: If they have access and interact, do they really participate?', CM-časopis za upravljanje komuniciranjem, 6:21, pp. 13-36.

(2015), 'Differentiating between access, interaction and participation', Conjunctions:

Transdisciplinary Journal of Cultural Participation, 2:2, pp. 7-28.

(2016), 'Beyond the ladder of participation: An analytical toolkit for the critical analysis of participatory media processes', Javnost - The Public, 23:1, pp. 70-88.

Carpentier, Nico, Lie, Rico and Servaes, Jan (2003), 'Community media: Muting the democratic media discourse?', Continuum, 17:1, pp. 51-68.

Chambers, Robert (1995), 'Poverty and livelihoods: whose reality counts?', Environment and Urbanization, 7:1, pp. 173-204.

Charmaz, Kathy (2014), Constructing Grounded Theory, London: Sage. 
Clarke, Adele E. (2007), 'Grounded theory: Critiques, debates, and situational analysis', in W. Outhwaite and S. P. Turner (eds.) The SAGE Handbook of Social Science Methodology, London: Sage, pp. 423-442.

Cleaver, Frances (2001), 'Institutions, agency and the limitations of participatory approaches to development', in B. Cooke and U. Kothari (eds.), Participation: The New Tyranny, pp. 36-55.

Cornwall, Andrea (2008), 'Unpacking “participation”: Models, meanings and practices', Community Development Journal, 43:3, pp. 269-83.

Couldry, Nick (2004), 'Theorising media as practice', Social Semiotics, 14:2, pp. 115-32. (2015), 'Alternative media and voice', in C. Atton (ed.), The Routledge Companion to Alternative and Community Media, London: Routledge, pp. 43-53.

Dahlgren, Peter and Alvares, Claudia (2013), 'Political participation in an age of mediatisation: Towards a new research agenda', Javnost - The Public, 20:2, pp. 47-65.

Department of Economics and Statistics (2017), Statistical Handbook of Tamil Nadu 2017, Chennai: Government of Tamil Nadu, http://www.tn.gov.in/deptst/. Accessed 20 May 2018.

Donner, Jonathon (2010), 'Framing M4D: The utility of continuity and the dual heritage of "mobiles and development", The Electronic Journal of Information Systems in Developing 
Countries, 44:1, pp. 1-16.

Dutta, Mohan J. (2014), 'A culture-centered approach to listening: Voices of social change', International Journal of Listening, 28:2, pp. 67-81.

Forde, Susan (2015), 'Politics, Participation and the people', in C. Atton (ed.), The Routledge Companion to Alternative and Community Media, London: Routledge, pp. 291-300.

Fraser, Nancy (1990), 'Rethinking the public sphere: A contribution to the critique of actually existing democracy', Social Text, 25:26, pp. 56-80.

Ghosh, Arijit (2011), 'Initiatives in ICT for rural development: an Indian perspective', Global Media Journal, 2:2, pp. 1-8.

Girard, Bruce (1992), A Passion for Radio: Radio Waves and Community, Montreal: Black Rose Books Ltd.

Gumucio-Dagron, Alfonso (2001), Making Waves: Stories of Participatory Communication for Social Change, New York: Rockefeller Foundation.

Hickey, Samuel and Mohan, Giles (2004), Participation - From Tyranny to Transformation?: Exploring New Approaches to Participation in Development, London: Zed books. 
Hussain, Faheem and Tongia, Rahul (2007), 'Community radio for development in South Asia: A sustainability study', in 2007 International Conference on Information and Communication Technologies and Development, Bangalore: IEEE, pp. 260-723.

Jacobson, Thomas L. (2016), ‘Amartya Sen's capabilities approach and communication for development and social change', Journal of Communication, 66:5, pp. 789-810 .

Katiyar, Kshitij (2017), 'Understanding community volunteering and representation: Case study of Waqt ki Awaz community radio station', 4th Annual International Communication Management Conference, Ahmedabad: MICA, pp. 324-39.

Kumar, Kanchan (2003), 'Mixed signals: Radio broadcasting policy in India', Economic and Political Weekly, 38:22, pp. 2173-82.

Kumar, Manish (2018), 'Unused funds choke India's struggling community radios', Asia Times, 19 June, http://www.atimes.com/article/unused-funds-choke-indias-struggling-communityradios/. Accessed 7 September 2018.

Kunreuther, Laura (2012), 'Aurality under democracy: Cultural history of FM radio and ideologies of voice in Nepal', in L. Bessire and D. Fisher (eds), Radio Fields: Anthropology and Wireless Sound in the 21st Century, New York: NYU Press, pp. 48-68.

Kusenbach, Margarethe (2003), 'Street phenomenology: The go-along as ethnographic research 
tool', Ethnography, 4:3, pp. 455-85.

Leontiev, Dmitry A. (2005), ‘Three facets of meaning', Journal of Russian \& East European Psychology, 43:6, pp. 45-72.

Malik, Kanchan K. (2012), 'Community radio: Eliminating voice poverty’, The Hoot, http://www.thehoot.org/web/home/story.php?storyid=5739\&pg=1\&mod=1\&sectionId. Accessed 14 August 2017.

(2016), 'Time for a Reboot', CR News, 20 September, http://uccommedia.in/news/timefor-a-reboot/. Accessed 14 August 2017.

Malik, Kanchan K. and Bandelli, Danielle (2012), 'Community radio and gender - towards an inclusive public sphere', India Media Symposium: Public Spheres, the Media \& Social Change, Brisbane, 21-23 November.

Meadows, Michael, Forde, Susan, Ewart, Jacqui and Foxwell, Kerry (2007), 'Community media matters: An audience study of the Australian community broadcasting sector', Brisbane: Griffith University.

Meadows, Michael, Forde, Susan, Ewart, Jacqui, Foxwell, Kerry and Morris, Christine (2005), 'Perfect match? Qualitative audience research and the community media sector', 3C Media Online, https://www.cbaa.org.au/article/perfect-match-qualitative-audience-research-and- 
community-media-sector Accessed 12 May 2015.

Ministry of Information and Broadcasting (2018), 'Operational CR stations', Ministry of Information and Broadcasting, https://mib.gov.in/sites/default/files/Operational CRS .pdf. Accessed 20 May 2018.

Nirmala, Yalala (2015), 'The role of community radio in empowering women in India', Media Asia, 42:1\&2, pp. 41-46.

Office of the Registrar General \& Census Commissioner (2011), 'Census data', Office of the Registrar General \& Census Commissioner, http://www.censusindia.gov.in/pca/Searchdata.aspx. Accessed 20 May 2018.

Page, David and Crawley, William (2001), Satellites Over South Asia: Broadcasting, Culture, and the Public Interest, New Delhi: Sage.

Pavarala, Vinod (2013), 'Ten years of community radio in India: Towards new solidarities', EduComm Asia, 17:2, pp. 2-4. (2015), 'Community radio “under progress"', Economic \& Political Weekly, 50:51, pp. 1417.

Pavarala, Vinod and Malik, Kanchan K. (2007), Other Voices: The Struggle for Community 
Radio in India, New Delhi: SAGE.

Prabakar, Neeraja (2009), A study on the role of campus community radio (Anna FM) in inculcating everyday science awareness among marginalised women', Chennai: Anna University.

Pretty, Jules N. (1995), 'Participatory learning for sustainable agriculture', World Development, 23:8, pp. 1247-63.

Ramalingam, Ben (2013), Aid on the Edge of Chaos: Rethinking International Cooperation in a Complex World, Oxford: Oxford University Press.

Rodriguez, Clemencia (2001), Fissures in the Mediascape: An International Study of Citizens' Media, New Jersey: Hampton Press.

SANCOM (2015), 'The community radio movement in India - a chronology of events', SANCOM, http://www.sancomonline.net/wp-content/uploads/2015/02/The-CR-Movement-inIndia.pdf. Accessed 20 May 2018.

Sen, Amartya K. (1999), Development as Freedom, Oxford: Oxford Paperbacks.

Sen, Ashish (2003), 'Waiting to be heard: Bringing marginalised voices to the centre', Economic and Political Weekly, 38:22, pp. 2198-201. 
Shah, Meera Kaul (1998), The Myth of Community: Gender Issues in Participatory

Development, Warwickshire: Practical Action Publishing.

Siemering, William (2000), 'Radio, democracy and development: Evolving models of community radio', Journal of Radio Studies, 7:2, pp. 373-78.

Singhal, Arvind and Rogers, Everett. M. (2001). 'India's communication revolution: from bullock carts to cyber marts', New Delhi: Sage India.

Spencer, Renee, Pryce, Julia M. and Walsh, Jill (2014), 'Philosophical approaches to qualitative research', The Oxford Handbook of Qualitative Research, New York, NY: Oxford University Press, pp. 81-98.

Tabing, Louie (2005), How to do Community Radio: A Primer for Community Radio Operators, New Delhi: UNESCO.

Tacchi, Jo (2009), 'Finding a voice: Digital storytelling as participatory development in Southeast Asia', in J. Hartley and K. McWilliam (eds), Story Circle: Digital Storytelling Around the World, Oxford: Wiley Online Library, pp. 167-75.

(2014), 'Being meaningfully mobile: Mobile phones and development', in J. Servaes (ed.), Technological Determinism and Social Change, Lanham, MD: Lexington Books, pp. 105-24. 
Tacchi, Jo and Kiran, Mulenahalli S. (2008), Finding a Voice: Themes and Discussions, New Delhi: UNESCO.

Tacchi, Jo, Kitner, Kathi R. and Crawford, Kate (2012), 'Meaningful mobility: Gender, development and mobile phones', Feminist Media Studies, 12:4, pp. 528-37.

Tacchi, Jo, Watkins, Jerry and Keerthirathne, Kosala (2009), 'Participatory content creation: Voice, communication, and development', Development in Practice, 19:4\&5, pp. 573-84.

Thomas, Pradip N. (2010), Political Economy of Communications in India: The Good, the Bad and the Ugly, New Delhi: SAGE.

Tufte, Thomas and Mefalopulos, Paulo (2009), Participatory Communication: A Practical Guide, Washington: World Bank Publications.

UNESCO (2011), Ground Realities: Community Radio in India (eds E. M. and R. Bhat), Bangalore: Communication and Information SectorUnited Nations Educational Scientific and Cultural Organization, http://unesdoc.unesco.org/images/0021/002173/217381e.pdf Accessed 9 May 2018.

White, Sarah C. (1996), 'Depoliticising development: The uses and abuses of participation', Development in Practice, 6:1, pp. 6-15. 


\section{Contributor details}

Bridget Backhaus is a lecturer in the School of Humanities, Languages and Social Science at Griffith University. She is interested in community radio and communication for development and social change. Her recent work focusses on how community radio stations engage their audiences and encourage participation.

E-mail: b.backhaus@griffith.edu.au

https://orcid.org/0000-0002-8244-2237 